\title{
'More than an academic thing': Becoming a teacher in Ltyentye Apurte and beyond
}

\begin{tabular}{|c|c|}
\hline Al Strangeways & Vivien Pettit \\
Charles Darwin University & Ltyentye Apurte Catholic School \\
alstrangeways@gmail.com & \\
\hline
\end{tabular}

Keywords: teacher education; Indigenous education; arts-based methods; narrative

\begin{abstract}
Becoming a teacher involves much more than building an effective collection of professional knowledge and practice. Establishing a satisfying and meaningful teacher identity is the foundation of teacher development and has implications for teacher retention and for reclaiming the profession from its current domination by policy discourses. Much can be learned by teacher educators, education leaders and teachers themselves from narratives of identity development. Such stories offer an embodied picture of the complex inter-relationship between the different elements of a teacher's identity and how a teacher's experiences, relationships and socio-cultural context shape the meaning they make of their teacherself. This paper draws on arts-based, narrative and dialogic methods to share Author 2's story of his professional identity formation before, during and after his participation in the Growing Our Own (GOO) program at Ltyentye Apurte (Santa Teresa).

The story emerges from data collected over six years of the eight-year working relationship between Author 2 and Author 1, a lecturer on the program. It casts light on the people, places and experiences that shaped his professional identity, on the challenges he encountered, and the impact becoming a teacher had on his identity as an Indigenous man and a member of his community. This story contests the notion of professional identity development as a straightforward journey towards a known destination and offers a rich embodiment of the complex nature of teacher identity as ecological, transactional and relative to time and place.
\end{abstract}

\section{Background and context}

\section{Teacher identity}

When Author 2 said, "It's more than an academic thing: it's about relationships and feeling good, feeling like you belong", he wasn't referring to his own learning. He was talking about his students' experience of school at the remote Indigenous community of Ltyentye Apurte (Santa Teresa) in central Australia where he learned to become a teacher as part of the Growing Our Own (GOO) program. GOO is a joint initiative of Charles Darwin University and Catholic Education, designed to deliver Indigenous teacher education 'on-country' and so address the shortage of remote Indigenous teachers. Author 2's insight into the relational and cultural aspects of his students' learning applies equally well to his own experience of learning to become a teacher.

Becoming a teacher is "more than an academic thing," and this is supported by the literature, which foregrounds the ecological nature of teacher identity formation (Beauchamp \& Thomas, 2009). Researchers and teacher educators are becoming increasingly aware that a teacher's development involves far more than the "acquisition of assets" such as skills, knowledge or beliefs (Akkerman \& Meijer, 2011, p. 308). Identity formation also involves the experience and negotiation of emotions, commitments and other elements that are not captured by a predefined set of professional standards. The post-structuralist recognition that identity is multiple and that it changes over time and in different contexts, offers a further layer of complexity to any inquiry into teacher identity formation or operation. 
These layers of complexity are one reason there is no agreed definition of teacher identity in the literature (Beijaard, Meijer, \& Verloop, 2004).

This paper's aim is to present and explore Author 2's story of becoming a teacher in order to: (1) demonstrate how recognising teacher identity as ecological, transactional and relative to time and place enables better understanding of the complexities of identity development; and (2) highlight the influences and challenges of beginning Indigenous teachers in remote contexts and the impact of becoming a teacher on their other identities and their community position.

\section{Ecological and post-structural conceptions of identity}

This paper frames teacher identity in terms of the ecological and post-structural conceptions of identity noted above, and expresses identity in terms of the model shown below (see Figure 1). This model draws on Mockler's (2011) understanding of teacher identity formation as an interplay between teachers' "motivations for entering the profession and their experiences as teachers" and involving personal experiences, professional contexts and political-cultural environments (p. 517). The model also embraces a dialogic understanding of identity as "both unitary and multiple, both continuous and discontinuous, and both individual and social" (Akkerman \& Meijer, 2011, p. 308). The implication of this dialogic conception is that teachers negotiate their identity positions within these dyads in response to the contexts and relationships of the moment. Identity is "an ongoing process of interpretation and reinterpretation of experience", an ever-changing answer to the recurrent question, "Who am I at this moment?" (Beijaard et al., 2004, p. 108).

Figure 1: Author 1's ecological and post-structural model of teacher identity

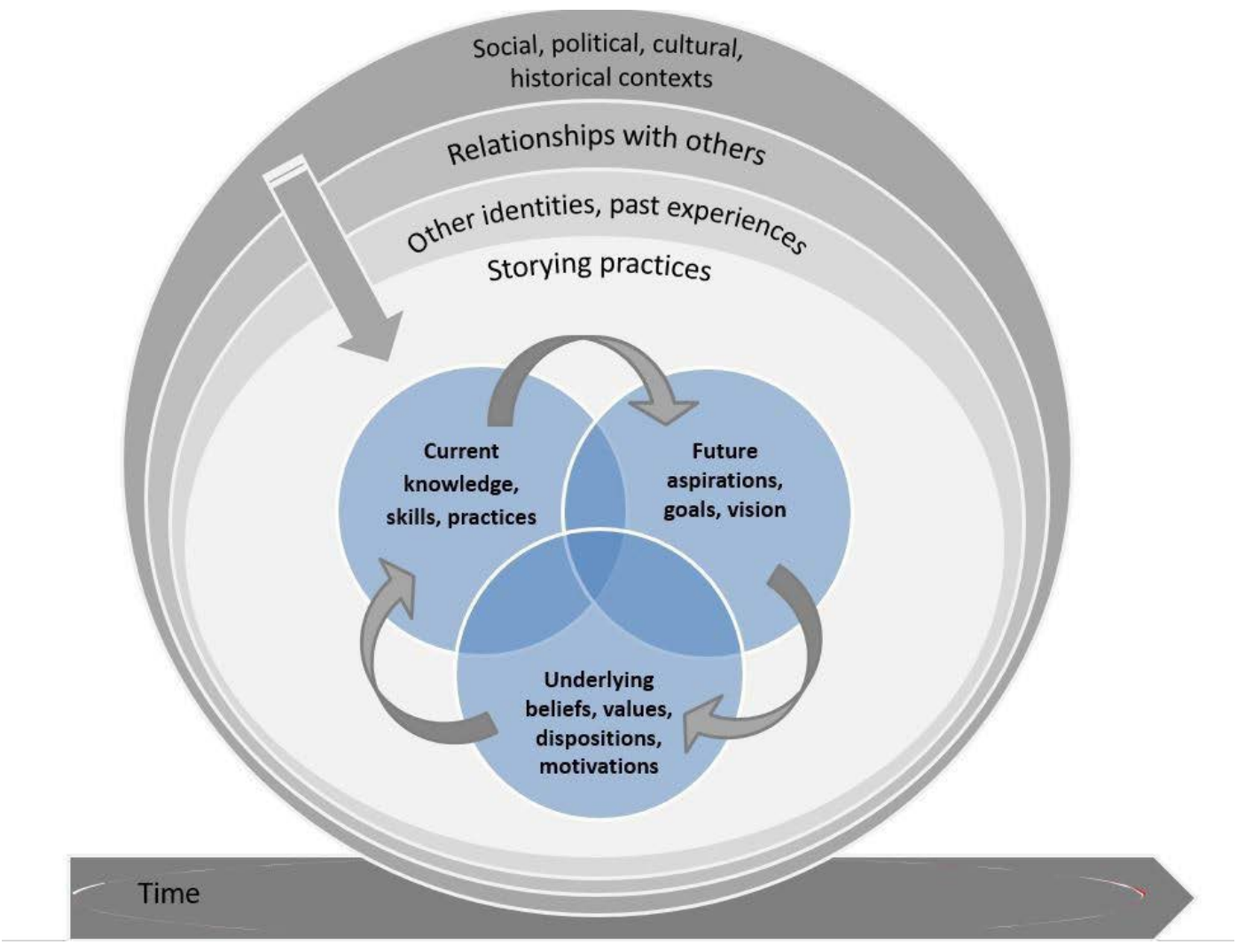

Source: Al Strangeways 
The teacher identity model created for this paper (Figure 1), identifies three inter-related elements of identity:

- Underlying beliefs, values, dispositions and motivations.

- Current knowledge, skills and practices.

- Future aspirations, goals and vision.

These elements are constructed through a series of ever-widening ecological spheres of influence (Bronfenbrenner, 1977), including: individual influences such as a teacher's storying practices; mesosystemic influences such as relationships with family and colleagues; and macrosystemic influences such as culture and history. The elements and influential factors of identity are all dynamic; they interact with each other and change over time. The purpose of the model is to express the individual elements of identity (the three inner circles of the model) and the ecological influences that work to construct these elements of identity (the four concentric circles and the timeline). The model draws on the ecological perspective that Strangeways and Papatraianou (2019) developed when re- mapping the landscape of teacher resilience. The spheres of influence described in the model need to be viewed and understood as ecological, transactional and relative; occurring in a socio-culturally constructed context, through a process of negotiation amongst contextually situated meanings and values, and changing according to these contexts and negotiations.

\section{Arts-based narrative and dialogic methods}

Teacher narratives have a long and well supported history in educational research (Goodson, 1990; Clandinin \& Connelly, 2004). They, along with other arts-based educational research (ABER) methods, are a key element of the "more nuanced and holistic approaches" to understanding professional identity that Mockler (2011) identified as essential to counter the increasing privileging of "technical-rational" understandings of teachers' work and role in policy and public discourse (p. 517). This paper uses narrative methods because identity itself is constructed by narrative. As Mockler (2011) asserted, narratives work both to produce identity, and to lay claim to it. Further, the knowledge that stories offer is always "situated, transient, partial and provisional" (Cormack, 2004, p. 220). This is because stories are the product of a series of reconstructions, by the participant who tells the story, by the writer who interprets the story in a paper such as this, and by you, the reader of the story. As such, narrative form serves well to represent the equally situated, transient, partial and provisional nature of identity, and the ecological system within which it develops and operates. As Clandinin, Downey and Huber (2009) asserted:

A narrative way of thinking about teacher identity speaks to the nexus of teachers' personal practice knowledge, and the landscapes, past and present, on which teachers live and work...using a concept of 'stories to live by' is a way to speak of the stories that teachers live out in practice and tell of who they are and are becoming as teachers. Important to this way of thinking is an understanding of the multiplicity of each of our lives - lives composed around multiple plotlines. (Clandinin et al., 2009, pp. 141-2)

\section{Dialogic approach}

Building on the work of Akkerman and Meijer (2011), this paper takes a dialogic approach to research methods as well as to the conceptualisation of identity. Dialogic inquiry is "an act of dialogue with the respective teachers," rather than research "about" them (Akkerman \& Meijer, 2011, p. 316). This paper is co-written with the teacher whose story it tells. Author 2's story is presented in the italicised texts, which were extracted from over 15 hours of transcribed interviews undertaken by him and his co-author, Author 1 who worked with Author 2 as his lecturer on the GOO program from 2010-2015. This period marked the end of his first year of full time teaching at the remote Indigenous community of Santa Teresa (Ltyentye Apurte) in central Australia. 
The analytic and interpretative text that forms the rest of this paper is the result of collaborative discussion between Author 2 and Author 1, as are the structure and themes that run through the narrative, analysis and artwork. Throughout this approach, the authors were careful that Author 2's story was not "colonized" in its retelling, so it maintained its authenticity whilst also serving the purposes of this research paper (Garrick in Cormack, 2004, p. 234). For this reason, we chose not to indent Author 2's text as "block quotation" to avoid relegating his voice to a supporting or illustrative position in relation to the interpretative and analytic text.

The care we took in maintaining the authenticity of Author 2's story was particularly important because much of it is very personal, and as Elbaz-Luwisch (1997) found, whilst "stories are most instructive when they are most personal," this is also the time "when the owners of the stories are most vulnerable" (Elbaz-Luwisch, 1997, p. 82). In addition to foregrounding the storyteller as co- constructor of this inquiry, a dialogic approach allows for analysis of both micro and macro spheres of identity. It recognises "the embeddedness of the lived experience in proceeding discourse and in situation and culture," and overcomes the unhelpful dichotomy between personal and professional identities, recognising instead the ways they inform and construct each other (Akkerman \& Meijer, 2011, p. 316).

\section{Narrative overview: from 'Drifting in' to 'Stepping out'}

This paper is structured around Eisner's arts-based educational criticism framework (1991), which operates to express an experience vividly, to interpret and evaluate it, and to draw out broader themes by locating the experience in the larger context of common concerns. The paper therefore draws on both types of narrative method, as articulated by Polkinghorne (1995). First, analysis of narrative, which views stories as data and analyses them for common themes; and second, narrative analysis, which views descriptions of events as data and generates stories by a process of emplotment, or selection and organisation of the events described into a narrative with a plot. This paper emplots Author 2's story as a sequence of four stages in his journey across the landscape of teacher identity: from 'drifting in' to the profession, to 'stumbling on' in his early years of initial teacher education, to 'stepping up' to managing the complexities of professional identity and practice, to 'stepping out' from the conventional classroom teacher identity and role. The narrative will highlight moments of re-construction or "epiphanies". These moments "alter and shape the meanings persona give to themselves and their life projects" (Denzin, 1994, p. 510). At these times Author 2 conforms to, resists or rewrites his culturally determined ways of talking, thinking and being (Denzin, 1994).

\section{Themes}

Within this plot, the paper foregrounds three main themes relating to the complexity of teacher identity formation and to the experiences of beginning Indigenous teachers. Two themes focus on the ways in which identity formation is rarely a straightforward journey across a clearly mapped landscape towards a single known destination. The paper demonstrates how recognising the relative-yet-unified nature of identity and the ecological-transactional aspects of identity formation offers a valuable lens through which to understand the complexity of this journey. The third theme is an implication of the ecologicaltransactional nature of teacher identity (Strangeways \& Papatraianou, 2019), in that it identifies the challenges facing remote Indigenous beginning teachers in negotiating often incongruent professional and cultural identities, and the impact becoming a teacher can have on their cultural identity and community position. The employment and theme analysis of the narrative is supplemented with an artwork created by Author 1 (Figure 2), where visual imagery has been used to more fully access the spatial, dynamic and ecological interconnections of the identity journey. The creation of this artwork worked both "to elaborate on the data...and to serve as [a] point of departure for dialogue" with Author 2, as we constructed this paper together (Leavy, 2015, p. 232). 


\section{The narrative}

For me, the core of good teaching is being honest and real about who I am and where I'm from. Making sure I tell students why I'm teaching and why they're learning. Why it's important. Also, being honest about what I know and what I don't know so I'm not faking or trying to be pretentious. And letting kids know it's alright not to know everything, and teachers don't know everything.

\section{Drifting in}

The whole reason I wanted to be a teach...that I decided to do the teaching and all that, was to help out. I wanted to come back and see if I can help out.

Author 2 drifted in to the teaching profession and for several years resisted identifying as a teacher, preferring to describe himself as "doing the teaching" as distinct from "being a teacher". Unlike many teachers, whose motivations for joining the profession are primarily an intrinsic desire to "be" a teacher (Chong \& Low, 2009), Author 2's entry onto the landscape of teaching and teacher identity was motived by more altruistic and extrinsic reasons. He described returning to Ltyentye Apurte:

At that time, 2006, I didn't know really where I was going, kind of between jobs, so I came out and just stayed with family, signed up for the CDEP [Community Development and Employment Program], but sort of with one eye over, looking at the school, like, "I wonder if they need any tutors or anything". Because you hear stories of low literacy, even now. I knew there was always that big gap, so I walked in and asked them if they needed any tutors, because at that time I was just going to do maybe one- on-one tutoring or just the basic literacy and numeracy. And they were like, "Yeah, you could. What's your name?" They found out I was Nora Hayes' son and they were like, "Yeah, no worries, come in".

There were two whitefellas teaching the seniors, a teacher and a TA [Aboriginal Teaching Assistant], and when I walked in my jaw hit the ground. They were both from Melbourne. Non-Indigenous. All the right criteria. One, burnt out and ready to leave; the other, brand new and a fish out of water. No people skills. It wasn't a good situation, so when the TA left that's when I started, not running the show, but taking on that role that I have ever since. I was just shocked, firstly at the students, at the lack of respect. When I was a kid here, there was always that respect for your elders, black or white. There was a generation of strong old men who you didn't mess with and this filtered down to everything. And I was shocked at some of the teachers too. What were they doing? Standing at the front and just talking. To no-one in particular. The range of levels in a class was huge but everyone was taught the same. And everyone would move up a year every year, no matter where their levels were. Why was it like this?

His later choice to join the GOO program in 2009 was also driven less by the intrinsic desire to "be" a teacher and more by extrinsic factors such as pay and conditions. He had little sense of the challenges that he would later encounter.

The school said, "There's this Certificate IV you can do, which if you do that, your pay will go up". So, I did that and moved up to AT [Aboriginal Teaching Assistant]. So that was really doing the same stuff but just getting holiday pay and benefits. And then this GOO thing came along and it was basically the same thing. "If you do this you will become a teacher and it would be a good piece of paper to have. And you know, your pay will go up", which is what everyone says, an incentive. So, I just said, "Yeah, no worries, I'll give it a go". I knew it was hard work to get a degree but I didn't realize how much work goes into it. I could do it, but do I want to do it sort of thing? Maybe l'd be happier being an AT.

Becoming a teacher was never an aspiration for Author 2, because school was not a significant place 
and the teachers he saw there were not people with whom he could identify. And yet, while he never saw himself in the identity of "teacher", many of the elements of his childhood can, in retrospect, be viewed as leading towards the landscape of teacher identity. In this sense, then, Author 2's teacher identity formation was ecological, rather than purely individual, "resulting from influences in a variety of contexts.... and at the same time representing the interactions of the elements of these contexts" (Sfard \& Prusak in Beauchamp \& Thomas, 2011, p. 7).

His teacher identity was constructed from his interactions with the people and contexts in which he was situated. It arose from his desire to help in the community and his sense of responsibility and comfort in the role of looking after and sticking up for the younger members of his family:

I'm comfortable with it [teaching], with parts of it. And it feels like it's always been that you know. Because growing up I was usually the eldest looking after the kids. So, I think that comes across you know. I think it's natural, and not very academic.

While Author 2 had no initial aspirations for himself, the motivation that formed his teacher identity in those early teaching days continued throughout his teaching degree. His motivations were primarily altruistic, to change things in the classroom and in the community, rather than to "be" an effective teacher. His aspirations, too, were for the school and the community rather than for himself as a teacher. Whilst the individual aspect of finding academic learning straightforward had some influence, the ecological aspects of his connections to family and community accounted for much more in this first part of his journey.

His sense of himself as a teacher contrasted with his understanding of the identity of "mainstream" teachers with the "right criteria". He was awkward with calling himself a teacher in his early years because those "right criteria" that positioned academic knowledge above relational skills, did not align with his beliefs about the importance of pedagogic relationships. In terms of Beijaard, Verloop \& Vermunt's (2000) framework of teacher perceptions of identity, Author 2 privileged the "pedagogic role" over "didactic knowledge" and "subject expertise". While Beijaard et al. (2000) pointed out that other teachers also privileging of pedagogic role was influential, they noted that this identity position usually occurred later in a teacher's career, as part of a shift from beginning teachers' identification with the role of subject matter expert. As a preservice teacher, Author 2 identified more with his students than with other teachers. $\mathrm{He}$ recognised this positioned him outside the expected practices of the profession and therefore the definitions of a "good teacher".

I don't think I'm a good teacher. I think I'm good at...just good with the kids sort of thing. I don't know what it is. Like relationships but some other word for it. Kids respond to the personality. They get a bit cheeky and I was, "I know all the tricks in the book" so l'd just say something smart-arsy back. Which I probably shouldn't have.

His rapport with students, particularly with those disengaged with schooling, was grounded in his own experiences of being a student. Paradoxically, then, the aspects of his identity that made him fit outside the parameters of the "good teacher", were the things that enabled him to make strong and effective connections with his students. His youthful disengagement with school and disrespect for institutional authority were aspects of his identity he drew on. His students felt drawn to him because they saw he was, in many ways, just like them. This was apparent when he evaluated his first Professional Experience placement beyond Ltyentye Apurte, in urban Alice Springs $80 \mathrm{~km}$ away.

I don't know if I was good [at teaching], but I had a good feel with them. Because I was just me. If you talk to kids in their language, you know, well those town kids, they saw that, saw me as someone they could relate to. And then because I spoke a bit of Arrernte too, a couple of the [Arrernte] camp kids were like, "Oh, you're from Santa Teresa." So, we made a connection there.

His sense of standing outside the traditional teacher role led to his focus on the practice of teaching rather than the identity of "being a teacher." This focus also highlighted his essentially democratic disposition as a teacher. 
My personality is like I don't want to stand up at the front. l'd rather be in the trenches, behind the scenes. Teaching to me is more of a guided discussion, where you [the teacher] are not someone bigger. Like you're teaching them, but it's not a teacher-student thing.

Author 2 recognised the incongruence between conventional notions of teacher identity and his own professional identity. In a similar way, he saw his cultural identity not easily fitting into the accepted mold. Returning to Ltyentye Apurte and becoming a teacher to "help out", was intrinsically bound up in Author 2's uneasy sense of himself as an Indigenous man with a white father and a mother who was a Traditional Owner.

\begin{abstract}
Because of the race, the identity and the whole light skin thing, it's bothered me for ages, because all the family's pretty dark and I'm like this, so where do I belong? I wonder what my family think and feel about me. Basically, I got sick of wondering, "What am I?" Men's business was a big part of it. If you go through it, it gives you a place and a status and a respect from the community. All my younger cousins were going through initiation. I should have gone through it before them. So it made me wonder, "Well maybe the men don't see me as what I thought they did." So, I challenged them on it. "What am I to you mob? I'm good enough when you come around looking for money, food and smokes, but am I too white for you mob?". Because in my mind, I wasn't coming out to Santa Teresa without being initiated, because you just need them stripes, you need that earned. You could be mocked or ridiculed and it would be like, "He hasn't been through it." It would make things uncomfortable. Make me uncomfortable. So anyway, it happened. That changed and gave me that direction. Now I could go out and live at Santa.
\end{abstract}

\title{
Summary
}

The story of Author 2's return to his community and his subsequent drifting into teaching draws attention to the ecological nature of professional identity and its formation. Author 2 recognised that, because of the ecological influences of his contexts and the interactions between these influences, his identity did not align with what he saw as the conventionally accepted identities of an Indigenous man or a teacher. This lack of congruence between his own sense of himself and the conventions of his cultural and professional identities was exacerbated by his firm belief in being "real" or honest about his identity. At this point in his journey, all three elements of his identity: his underlying motivations, his current teaching practices, and his future aspirations; were determined more by the social than the individual spheres of his ecological system. His motivations were primarily to help the community, and his practices and aspirations were to advocate for others. He had no aspirations to "be" a teacher. Whilst his mother had worked in education support when Author 2 was young, he had never viewed her as a teacher. There were no Aboriginal classroom teachers when Author 2 began work as a tutor in school, and no male Aboriginal Teaching Assistants. He therefore had no teaching role models with whom he could identify or aspire to. It is not surprising then, that his entry into the profession took the form of 'drifting in.'

\section{Stumbling on}

Don't put me on this pedestal...I'm just like you...I'm not this perfect thing.

Author 2's journey to becoming a teacher was not smooth. At different times and in different contexts, he encountered challenges that caused him to stumble, or left him simply 'stumbling on,' at odds with the vision others had for him as a teacher. The intertwining of Author 2's personal and professional identities, coupled with his belief in being honest with his students, presented considerable challenges on his journey to becoming a teacher. Although his motivation in returning to Ltyentye Apurte was to help, he was deeply concerned about how his return might be viewed by the Indigenous and non- Indigenous community. 
that I was this great white, well not white, but great hope, come back to save the people. Because family was like, "Ah, you're at the school. We need you to be here." Because I am who I am and my skin colour and all that, you stand out. So, there's been a couple of times when l've purposely run amok to let people know that l'm not here as a savior..."I'm just like you. I've got my own things and l'm not this perfect thing." People got that pretty quickly when l'd come back from the [community] boundary after fights and with black eyes and whatever.

As Santoro and Reid (2006b) suggested, the struggle for Indigenous teachers to establish teacher identity,

is complicated by the teachers' identity positioning within their own Indigenous communities and the set of expectations that are placed on Indigenous teachers by parents and community members who see them as potentially mediating or changing the Whiteness of schooling in ways that will benefit their culture. (Santoro \& Reid, 2006b, p. 144)

Similarly, in the eyes of the non-Indigenous community, expectations were high. They failed to recognise what Santoro and Reid (2006a) identified as the "complexities [facing Indigenous teachers] of identifying with both school and Indigenous communities" and the "gulf between community and school [which] can cause problems that many Indigenous teachers are unable to resolve" (p. 295). When the GOO program started, an Alice Springs newspaper sent a reporter to the community for a story that focused on Author 2 , the only male in his group of Indigenous preservice teachers.

They tried to put me on this pedestal or something. It was funny to me. I was just happy to do what I was doing. They were like, "This is so great. You're doing this for your people." And I was like, "No don't put me on this pedestal." I was really against them trying to make me out to be something that I wasn't. Like some people are on posters, you know: "Don't do this," or "You should do this," and I knew enough to go, "Don't paint me to be something that I'm not, because I come from town and l've been involved with all kinds of stuff - drinking and smoking [weed]." They didn't want to put all that stuff in the article, but it's real. It's real you know. Back then, I was like, I'm not a role model. But you are. If you go into that teaching thing, you are. Whether you like it or not. But I was against it back then.

For Author 2, embracing the reality that, as a teacher, he was a role model for his students and for the community, was a significant turning point in his journey. He recognised the impossibility of separating his identity in the classroom from who he was outside of the school. He accepted that "the me, good and bad, will flow on to the teacher." It was also a point that brought him to an identity landscape of increased ambiguity and complexity. Embracing the responsibility of being a role model was accompanied by the recognition of a further reality. As the teacher, the responsibility for much of what was challenging in the classroom was his; either directly because of his behaviour in the classroom, or less directly but equally powerfully, as a member of the community whose behaviour was not always exemplary.

His dilemma was managing the tension between fulfilling his belief in being authentic in the classroom, and being a role model. When considering his first Professional Experience teaching placement outside of the community in an urban school, he reflected,

I knew what I didn't what to go in as: the whole, "Ah hello kids. Alright, today we are going to be learning about... and if you open up your books." That real stiff stuff. I'm not going to go in there and pretend to be, or try and do something that l'm not. More important than delivering a perfect lesson to me, is making that connection to that kid. That's where my heart is when it comes to teaching. Like $f^{* \star *}$ the latitude and longitude [learning topic]. Who cares. If the kid's, you know, had a good lesson, he had a good day. I'm not invested in the academic; I'm more invested in the student.

In this, Author 2 aligned with what Santoro and Reid (2006a) described as the "identity position of 'the Indigenous teacher'," which, they argued, is often "assigned" to Indigenous teachers "at the expense of any other identity and role as 'teacher'." (p. 298). In this role, they are expected to have primary expertise 
in cultural and relational areas at the expense of other skills and knowledge. While this identity can be constricting if assigned, as was the case for Santoro and Reid's interviewees, Author 2 embraced this identity position and challenged the conventional bias he saw that placed academic capacity above student wellbeing and relationships.

Author 2's recognition of the importance of authentic relationships presented challenges for his ethics and practice. He needed to fulfil his need to "be real" in the classroom, and a person with whom the students identified. He also needed to accept and embrace his status as a community role model. It was not a dilemma that could be resolved because of the ecological nature of professional identity, and the connectedness of his remote Indigenous context, where, as Author 2 asserted,

\section{Everything's connected: everything affects everything else in this place.}

Because of the ecological nature of identity, Author 2's teacher-self was the result of an ongoing series of transactions between different elements of his identity and contexts. There was no perfect balance to be achieved between embracing his professional position and being honest about his personal struggles with anger and substance abuse; struggles with which many in his community also dealt. Instead, his professional identity was constructed as an ongoing series of identity positions that were constantly negotiated and re-negotiated.

\section{Transactional negotiations}

The transactional aspects of Author 2's identity development can clearly be seen in the uneasy identity negotiations involving his conflicting professional and community positions, and his incongruent commitments to authentic relationships and responsible role-modelling. An equally challenging aspect of his identity development was the transactional negotiations between his teacher and cultural identities that centred around his obligations as an Indigenous man and his responsibilities as a teacher. Strong cultural structures of inter-personal obligation to members of his immediate and extended family operated to shape his identity and the routines of his daily life, in both supportive and restrictive ways.

I've always had that thing, you know, that the other [white] teachers don't have to deal with. Like a phone call from family, saying, "Son, I need money for food or bills," or knowing your cousin needs rent-bond money or a car so they can do the right thing by their kids. Or having to make more and more space in a one-bedroom teacher flat because family need a place to stay. You know, "blackfella" things. But one of the main reasons I came back here in the first place, was to spend time with family and reconnect with my culture: go out bush, go hunting with the uncles. But that didn't happen as much as it used to. I also need to make time for people like my cousin-brother, be a good big brother to him. But lately, it's like I don't have the energy for any of that after school. For the things I came back for. All the energy goes into the school and l've got nothing left. l'm just Grumpy, and I don't want to be that.

Santoro and Reid's (2006) research reflected some of Author 2's experience when they suggested that:

...remaining in their own country appears to help teachers overcome some of the problems that arise from the assumption of a generic Indigenous teacher identity who is expected to solve 'all the problems' just because they are known to be Indigenous...their work is enhanced by the relationships of kinship and family, even though these can sometimes be taken for granted by the system and taken advantage of by the community...they do have emotional support in their homes from the struggle that their position often entails. (2006b, p. 157)

For Author 2, however, the nature of his teacher role and identity curtailed some of the opportunities to access this relational and emotional support. The way that Author 2's cultural obligations and connections as an Indigenous man impacted in both supportive and restrictive ways on his teacher identity was an important aspect of his teacher identity development. Similarly, the significant human losses he experienced, in his final years of the GOO program and first years of qualified teaching, both challenged 
his sense of purpose and increased his resolve as a teacher. The deaths of two close family members and that of his school principal were both emotionally destabilising. In the case of the loss of his principal, Kwementayaye Crowe, it removed a key mentor, champion and professional support, someone who Author 2 knew would always "have my back", even when Author 2 did not live up to his own and others' expectations. Equally, however, these losses also became motivations to justify the belief these people had in him as an Indigenous man and a teacher, to honour his memories of them, his relationships with them and their belief in him.

\section{Stepping up}

Me the person is getting better as a person, and Me the teacher is getting better as a teacher, so they go together.

Author 2 continued at times to stumble on the ongoing challenges of negotiating obligations, managing his struggles with his cultural identity, substance abuse and the human losses he experienced. Many things, however, changed as Author 2 stepped up and moved closer to becoming a qualified classroom teacher. The passage of time, his experience of different school contexts, and his change in status from preservice to qualified teacher all modified aspects of his professional identity. However, the core elements of his professional identity in terms of his beliefs, his practices and his aspirations, and the central tensions within his ecologically-influenced identity remained constant. In this way, as Akkerman and Meijer (2011) attested, his identity was both continuous and discontinuous, or both unitary and relative to context.

The two final Professional Experience placements that Author 2 undertook as a preservice teacher were away from his community. These placements in Alice Springs, and in central New South Wales, instilled confidence that he could "teach anywhere, not just at Santa Teresa".

I knew I was good with the kids out here [Ltyentye Apurte]. And I thought it was just out here, so I was freaking out a bit about going into [the Alice Springs school]. But then I was just "myself" there as well, and I don't know if I was good, but I had a good feel with them...The main thing I took away from [the NSW placement] was the different experience and knowing I could survive in this environment if I wanted to. The things I use at Ltyentye Apurte, it was good to see that they worked there. That balance of visual, discussion and doing, that was pretty much the model for all of our lessons, because that's a good balance. They get to see something, then talk about it, and they get to show they understand it.

In both placements he was able to apply his skills in making authentic connections to students with whom other teachers often struggled to engage. In these different contexts too, his dispositional orientation towards supporting students with additional behavioural and/or learning needs was consolidated.

Those [disengaged] kids. They're the ones going, "Hello Mr P!" The other teachers were like, "They never talk like that to anyone else. They usually run amok. They switch off or they don't listen." But I always gravitate towards them and always have good relationships with them. Maybe l'm giving them that extra. Not extra time, but that [particular kind of] time. Acknowledgement of who they are. It can be a look, a smile, a quick comment or question about something that matters to them. And, as I go through this journey, I want to do more of that.

In the very different context of NSW too, he stepped up in his focus on academic learning outcomes. Instead of viewing academic and relational aspects of teaching as in conflict, he began to employ his capacity to support socio-emotional learning in order to build academic learning outcomes. He described his use of visuals in a lesson on the extremes of poverty and wealth as a way for students.

...to make the emotional connection [to the topic] so they want to start asking the questions themselves. Because then it's real to them, what's happening in the world, from seeing the pictures and thinking. 
He also recognised that, as he became more committed to "the academic" side of teaching, his commitment to authentic relationships extended to influence his pedagogical practices.

The thing with me is if I'm teaching something, I want to be invested in it. I don't want to just, "OK, we're doing molecules and whatever today, just read and answer the questions." If I'm genuinely interested in the thing, the lessons are better because of this. I did a lesson with the extremes of poverty and wealth. I got the idea from talking to someone in the launderette about, "How can people be starving in the world and yet there are eating competitions where people get paid thousands of dollars?" And that was it, bang! I thought, that's perfect for this lesson on what I'm going to do on extremes of poverty. There's wanting to show kids, wanting to tell them, wanting to do that. Whereas if it's something you're not interested in, like salinity, of course it's going to affect things. And the kids know. I can't sell this.

Author 2's identity was constant in his commitment to the authentic relationships in teaching. However, as his contexts changed, he became increasingly committed to delivering authentic content in lessons, and began to focus on developing his planning skills and practices. When he returned to Ltyentye Apurte, it was with a clear sense of academic mission.

We have to load them up with skills and knowledge regardless of whether they use it or not, they have the right to know, to learn and have skills because you never know, we're dealing with human beings here. So, planning's just natural now. It's not like, "Oh I have to do it." It's got to be done if I want to get the best out of the class, each class, not just today but each class and the follow-on lesson, where we are going next and all that. The thing that scares me the most, and should scare every teacher, is going in unprepared. It's the worst. Teaching on a whim.

Author 2 recognised it would take time to convince his colleagues of his increased pedagogical commitment. It would involve him stepping out from the identity position he inhabited as a result of his past behaviours. This was made harder because of the kinds of institutionalised racism identified by Hall (2016), which holds Indigenous teachers "at arm's length, treated as 'white but not quite' according to the theory of colonial mimicry" (p. 336).

I understand because of my past, my irresponsibility, people might take a bit longer to go, "OK, he's serious." But I want to do all that questioning: "Why exactly are we doing this activity?" Or saying, "I don't think we should be doing this activity with the kids here." And people might joke about it: "Oh look at you, look at the big words you're using now."

Equally as significant as his changes in geographical context was Author 2's change in status when he completed his teaching degree and took responsibility for his own class. For more than a year before he qualified, he recognised the requirement that qualification represented; to embrace the responsibilities of a classroom teacher.

After his first year of full-time teaching, he reflected on the changes he underwent:

I always knew it was step-up time when I got my own class, so that combination of knowing it was coming, and then it came and it was: "Let's do it. You're that person now. You can be that person now, who you always planned to be when you got there."

From stepping up as a teacher, Author 2 also saw himself making personal gains, which in turn fed into his professional practice. He recognised he was now "a calmer influence in class," and a teacher who could better fulfil his commitment to instinctual teaching because he could:

...follow my instincts better because my own $f^{\star * *}$ ups haven't been on my mind, which is probably fifty percent of the reason I would blow up at the kids years ago, because I had my own $s^{* * *}$, drinking issues, the identity thing. And I just see myself as getting calm and liking myself more, liking the person who I am now more than the $f^{\star * *}$ up that was years ago. People would say its maturity. I don't know what to call it - just liking myself. It's like seeing 
yourself turning into the person you always wanted to be. It's kind of freaky for me, but it feels good to be turning into that person.

Stepping into the classroom as a qualified teacher did not re-direct his thinking but rather:

...reinforced my thinking of the problems with the school and this place. Because I saw it from when I first walked in. I saw the problems but I just didn't see the reasons. It's clearer and clearer, the reasons now. And that's positive because you can change it. Or try. Go down trying, or swinging or whatever. And I guess the more experienced I get, the more I know, the more noise l'm going to start making. Because it's needed. And you need to. It needs to be challenged, this way. Even though people's hands are tied, or they think they are. People know we should be doing things differently, but they don't, we don't. Why is that? I think the system won't change. But I think you need to try whatever works, you need to try different things. And every school's different. Every community's different. Sometimes, what works somewhere else doesn't mean it's going to work here. So, you need to be flexible.

Another significant change in Author 2's way of thinking about "the problems with the school and this place" occurred shortly before he graduated as a teacher. It was the result of a single conversation with his principal at the time, Brother Daniel. Author 2 described this conversation as a moment of epiphany:

I was getting angry with kids and angry with my family. It was all sort of coming up from all angles and I said to Brother, "Brother, I don't know if I can keep going, keep doing this, because I don't want to start hating this place and hating the kids, or hating the school, or hating everything." And he spun it in a way that changed my thinking. He said, "That's true what you're saying but just imagine you weren't in their lives. If you weren't being that boundary for them. Where would they end up?" And that made me think totally differently, make me flip my thinking and it actually gave me energy to keep going. The understanding that it's the way you think about things and which way you're looking at something. That's changed me. Not wasting energy on the negative...Instead, accepting and changing the way you look at something. That's been my main change. So now, l've just gotta do that work, put in that extra, because that's what's needed. It's changing it from yourself, to shining that light from yourself out. It's a change that has made me a better person. And happier, because it doesn't feel like l'm going against the grain. I'm going with the grain but l'm kind of more in control. Change the way you look at something if you want it to change.

\section{Summary}

Author 2's stepping up in his professional identity was influenced by his external teaching placements, becoming a graduate teacher, and choosing a positive perspective. He also recognised the impact these changes in context had on his attitude toward "helping out". When he graduated, he reflected:

Teaching has changed for me a lot from when I first started. I came out with the mentality, "I'm just going to help people because they need it out on the community, on Mum's community." But now I realise I was the one that needed the help just as much, with getting myself together. And it's that realisation, that basically it's a two-way street, that l've gained. And I have to take as much as I can from this learning journey to become a better teacher, but more importantly a better person.

\section{Stepping out}

I know there's a big job here to do...l always want to be connected to the school, whatever I'm doing in the community. I'll always think of myself as a teacher in some way, even if I'm not teaching. 
After two years working in the school as a full-time classroom teacher, Author 2 chose to step away from the role. He remained at the school, but returned to the position of an Aboriginal Teaching Assistant, working in the classroom of a newly arrived non-Indigenous teacher. He became more involved with community matters such as coordinating various agencies' delivery of their school holiday programs, involving the community men more closely in school matters, and facilitating community discussion about social issues such as drinking and children on the streets at night. Author 2 did not see his choice to step out as a rejection of his teacher identity, rather it was an affirmation of the ecological connectedness of his own identity within his community. The commitment to community that originally motivated his 'drifting in' to teaching also motivated his 'stepping out' from the school into broader community concerns. Because of his Indigenous and Anglo-Australian heritage, he had always felt a keen sense of responsibility to help improve things in the community:

That's been my number one thing. Not burden, just constant worry, I have to have a crack at changing things because people see me as black and white. I walk in both sides and all that and I need to use that. I have to because my family can't do it, whitefellas can't communicate with blackfellas, so the pressures on me.

As Santoro and Reid (2006b) noted, "It is highly unlikely that there are supports of [Indigenous] teachers in these positions as they are most likely to be the only such intermediary person in the community" ( $p$. 156). This was certainly true of Author 2's experience. He recognised that, while his heritage gave him a "unique perspective and a shortcut to building rapport" in both the classroom and the community, it also brought conflicting demands from which he could not step back. He reflected on his experience of balancing his work at school, with trying to bring different service providers and stakeholders together to discuss drinking in the community:

It's frustrating, because, really, organising a meeting is not that hard, but no-one else is doing it, so l'm running around all afternoon which is pulling me in different ways. It's that thing I knew was going to happen once you put your hand up for something: everyone looks to you for everything else then.

Santoro and Reid (2006a) asserted that it is this "extra workload and the emotional stress associated with the expectation to be 'all things to all people' that has the greatest influence on Indigenous teachers' decision to leave teaching" (p. 298).

Author 2 recognised that stepping up at a community level meant full-time teaching would be increasingly less sustainable for him. He also stepped out from the school because he found it hard to justify his authenticity in the classroom if he were not involved in broader community and cultural issues. Near the end of his second year as a classroom teacher, he reflected:

I don't know if I have the same drive, as much of the drive as I did in my first year. I have stepped up involvement in community issues...like outside of school...that are affecting the school. Things that are happening, like the drinking and the youth in the community having nothing to do, or nothing to work towards. There's no real employment options and there's no real willingness to go look for work or go outside the community. I can talk till I'm black and blue about, "When you leave school this is helping you," but if we're still struggling to get housing, we're still struggling to get employment, and there's no real industry to move into or motivation, then you know, what's the point.

Author 2 saw that supporting the changes he envisioned in his community involved embracing the connected and often conflicting responsibilities that wove through his professional, cultural and personal identities. He remembered the excitement of his class in his first year as a teacher as they brainstormed things to improve community liveability:

That's what I mean by big things in the future, because I'm now capable of doing things to help out and helping myself too in the process. I genuinely want to help my mob and I couldn't do that if I was the same person I was five years ago, because you need to not only say but do as well, and you need to be that example. I can't be that same person [the drinker 
and fighter] if I want those big things in the future, to help my mob.

\section{More than an academic thing}

Kids wanting to be at school, I mean in your class, that's big for some kids here. And to know it's because it's how you make them feel when they're in the classroom. I can be tough on them but they know it's fair and they know l'll look out for them whoever it is - boy, girl, family, non-family -- they know that it's a neutral zone. If they do the right thing then we're $\mathrm{cool}$, we're safe and the boundaries are there. So, it's been good to see kids that weren't hardly here before, but now because they feel that way they want to be at school. And that's also more than any academic thing, I think.

Author 2's motivations as a teacher stemmed from his commitment to his community but also to the socio-emotional development of his students that he saw as "more than any academic thing." So too, the path he took to becoming a teacher (and beyond) covered a more complex landscape and resulted in more significant personal changes than that of a simple journey towards acquisition of the skills and practices of the profession.

\section{Art-based analysis}

The artwork below (Figure 2) presents an alternate way to understand both the landscape of teacher identity and Author 2's journey across it, acting as a companion to the narrative. The following interpretative comments are offered as an invitation to your own engagement with the image, and a visual re-framing of the story that has come before.

The landscape represented, of a central Australian range, perhaps rising from an ancient claypan, can also can be read as a map across whose contours key places in the landscape are named. This landscape is constructed of layers, where the lithosphere of "knowledge, skills, practices" rests between the often-hidden geology of "values, motivations, dispositions" and the airy atmosphere of "aspirations, goals and vision." Running perpendicular to this geological cross-section are the other named features of this place over which the journey occurs, "ecological, transactional, relational."

As we shift from reading the horizontal phrases to reading the vertical words, we shift in our perspective from seeing a landscape to seeing a map. Look closer, and the trails that thread their way across this landscape are also names, forming, over and over, the threads of a journey from 'drifting in', through 'stumbling on,' to 'stepping up' to 'stepping out'. These pathways seem both to clamber across the range, and to have their route shaped by the contours of the map. In this, the artwork attempts to articulate what writer and artist Kim Mahood (2016) described as the "tension between ways of seeing the landscape. The perspectival [European, imperial view] of foreground, middle ground and horizon, and the bird's-eye view of a schematic, inhabited topography [a feature of much Australian Aboriginal landscape art] [which] mirrors the tension between ways of being in the landscape" (p. 294). As well as the ontological tension of "being" in both Western and Aboriginal cultures, the artwork also expresses Mahood's conception of landscape as one "where map and metaphor become the same-smoke and mirage, shadows and absences, through which meaning slips like light" (2016, p. 295). The artwork represents how identity and identity development is resistant to fixed or certain meanings, and how, therefore, we need to continually question, make and remake such meanings that are offered. 
Figure 2: Author 1's mixed media artwork, 'From "drifting in" to "stepping out": Journeys across landscape of teacher identity.

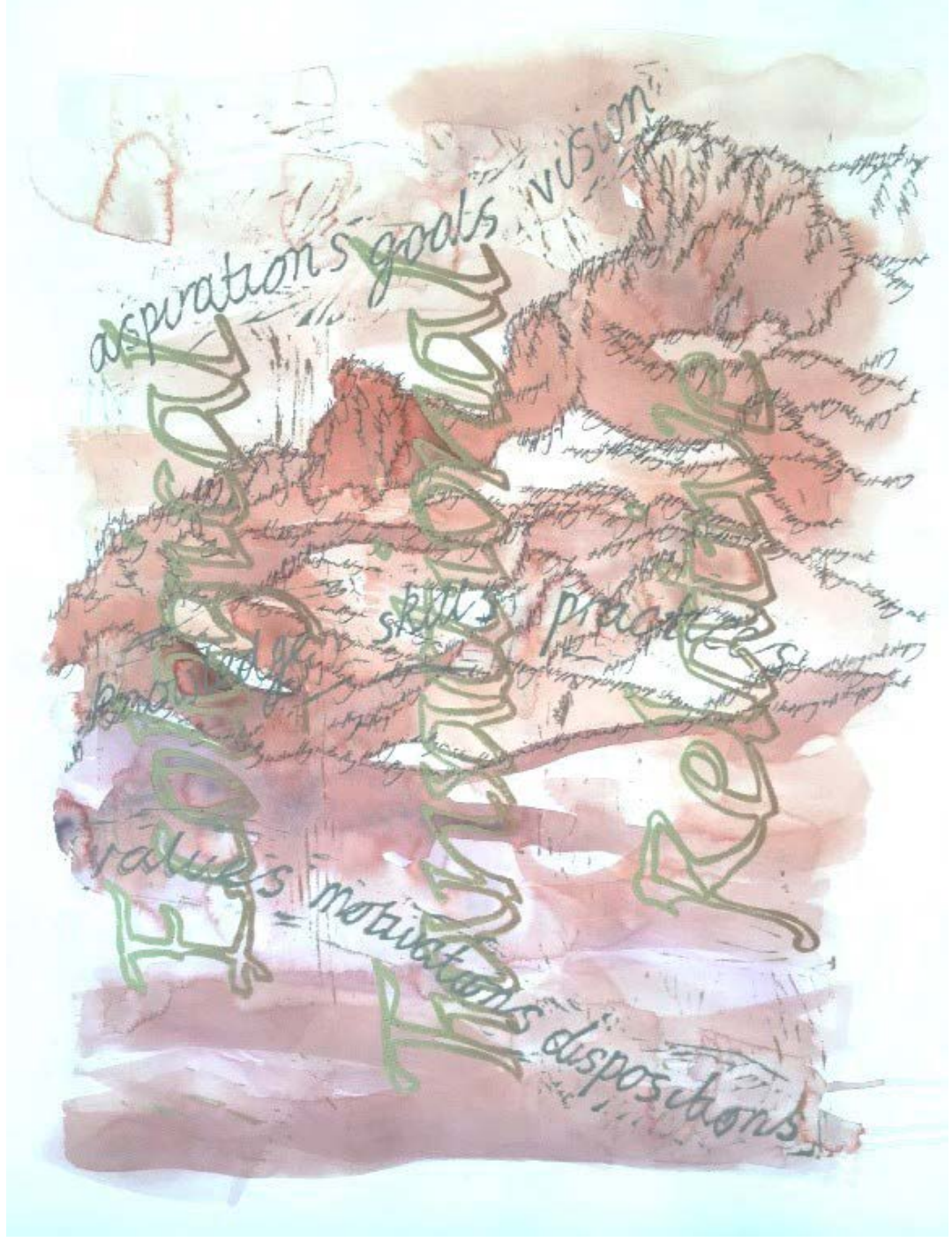

Source: Al Strangeways

\section{Insights and learnings}

The story of Author 2's journey has foregrounded three main insights relating to the complexity of teacher identity and to the particular challenges faced by remote Indigenous teachers.

First, teacher identity is both relative and continuous. Author 2's underlying beliefs, current practices and future aspirations were modified across the changing times and places of his journey. The three commitments that characterise his identity were however, evident from the beginning and sustained through all these changing contexts. These were: his desire to 'help out' and subsequent embracing of the responsibilities of teacher, colleague and community member; his commitment to relationships; and his determination to take an authentic approach to relationships and pedagogy. Each of these three commitments changed relative to Author 2's professional and cultural contexts, and to each other, as he negotiated who he was, and what he would do to best fulfil them.

Second, teacher identity is ecological and also transactional: it consists of individual and socio-cultural factors and is constructed and reconstructed in a series of transactions between these factors in different 
situations and for different purposes. Author 2's journey was shaped by the ecology of socio- cultural factors, which also constructed his professional identity. As such, personal and socio-cultural factors including his Indigenous/Anglo-Australian heritage, the culturally embedded expectations of familial obligation and of teacher professional values, were inseparable from his underlying values, his current practices and his future aspirations.

Third, a significant implication of the ecological-transactional nature of teacher identity relates to the differences between Indigenous culture and the western culture of schooling. Aboriginal teachers, and particularly Aboriginal teachers located in their remote home community, encounter specific challenges and tensions in negotiating an inter-cultural professional identity. These challenges are currently not fully understood or supported by initial teacher education providers or school communities. As Fredericks (2002) challenged us to recognise:

Aboriginal people live in the contemporary world and weave in and out of two, three and even more cultural domains. We are part of colonisation, just as it is part of us...You might have to look and listen more closely, but culture is always there in some form, always was and always will be. (Santoro \& Reid, 2006b, p. 148)

\section{Conclusion}

Becoming an Indigenous teacher in one's own remote community brings with it a unique set of motivations and challenges unfamiliar to individuals outside that situation. The "walking in two worlds" that Author 2 undertook as a man of Indigenous and Anglo-Australian parentage brought with it challenges and particular responsibilities to negotiate intercultural communication, collaboration and identity. Further, being both a classroom teacher and a member of his community brought a range of often competing professional, familial and cultural obligations.

Becoming a teacher meant negotiating the professional responsibilities of a classroom teacher and the familial and cultural obligations of an Indigenous man. While his original motivations to become a teacher stemmed from his commitment to community and family, his decision to give up full-time classroom teaching was also motivated by the same ecological identity that integrated being a teacher, a son, a nephew, a cousin, an uncle and a Traditional Owner. Such complexities of Indigenous teacher identity need to be better understood and more fully considered if Australia is to attract and retain the Indigenous teachers needed in our schools into the future. 


\section{References}

Akkerman, S.F., \& Meijer, P.C. (2011). A dialogical approach to conceptualizing teacher identity. Teaching and Teacher Education, 27(2), 308-319.

Beauchamp, C., \& Thomas, L. (2009). Understanding teacher identity: an overview of issues in the literature and implications for teacher education. Cambridge Journal of Education, 39(2), 175-189.

Beauchamp, C., \& Thomas, L. (2011). New teachers' identity shifts at the boundary of teacher education and initial practice. International Journals of Educational Research. 50, 6-13.

Beijaard, D., Verloop, D., \& Vermunt, J.D. (2000). Teachers' perceptions of professional identity: an exploratory study from a personal knowledge perspective. Teaching and Teacher Education, 16, 749-764.

Beijaard, D., Meijer, P.C. \& Verloop, N. (2004). Reconsidering research on teachers' professional identity. Teaching and Teacher Education, 20, 107-128.

Bronfenbrenner, U. (1977). Toward an experimental ecology of human development. American Psychologist, 32(7), 513.

Chong, S., \& Low, E. (2009). Why I want to teach and how I feel about teaching: Formation of teacher identity from preservice teacher to beginning teacher phase. Educational Research, Policy and Practice, 8, 59-72.

Clandinin, D.J., \& Connelly, F.M. (2004). Narrative inquiry: Experience and story in qualitation research. Francisco: Jossey-Bass.

Clandinin, D.J., Downey, C.A., \& Huber, J. (2009). Attending to changing landscapes: Shaping the interwoven identities of teachers and teacher educators. Asia-Pacific Journal of Teacher Education, 37(2), 141-154.

Cormack, A. (2004). Storying stories: A narrative approach to in-depth conversations. International Journal of Social Research Methodology, 7(3), 219-236.

Denzin, N.K. (1994). The art and politics of interpretation. In N.K. Denzin \& Y.S. Lincoln (Eds.) Handbook of Qualitative Research. Thousand Oaks: Sage Publication, 500-515.

Eisner, E. W. (1991). The enlightened eye: Qualitative inquiry and the enhancement of educational practice. New York: Macmillan.

Elbaz-Luwisch, F. (1997). Narrative research: Political issues and implications. Teaching and Teacher Education,13(1), 75-83.

Goodson, I.F. (Ed.). (1990). Studying teachers'lives. London: Routledge.

Hall, L. M. (2016). Moving Deeper into Difference: Developing Meaningful and Effective Pathways Into Teacher Education for Indigenous Adults from Remote Communities (Doctoral dissertation, Charles Darwin University).

Leavy, P. (2015). Method meets art: Arts-based research practice (2nd ed.). New York: The Guilford Press.

Mahood, K. (2016). Position doubtful: Mapping landscapes and memories. Brunswick, VIC: Scribe.

Mockler, N. (2011). Beyond 'what works': Understanding teacher identity as a practical and political tool. Teachers and Teaching: theory and practice, 17(5), 517-528.

Polkinghorne, D.E. (1995). Narrative configuration in qualitative analysis. Qualitative Studies in Education, 8(1), 5-25. 
Santoro, N., \& Reid. J. (2006a). "All things to all people": Indigenous teachers in the Australian teaching profession. European Journal of Teacher Education, 29(3), 287-303.

Santoro, N., \& Reid. J. (2006b). Cinders in snow? Indigenous teacher identities in formation. Asia-Pacific Journal of Teacher Education, 34(2), 143-160.

Strangeways, A., \& Papatraianou, L. (2019). Remapping the Landscape of Resilience: Learning from an Arrernte Teacher's Story. Journal of Intercultural Studies, 40(1), 16-31. DOI:

10.1080/07256868.2018.1552569

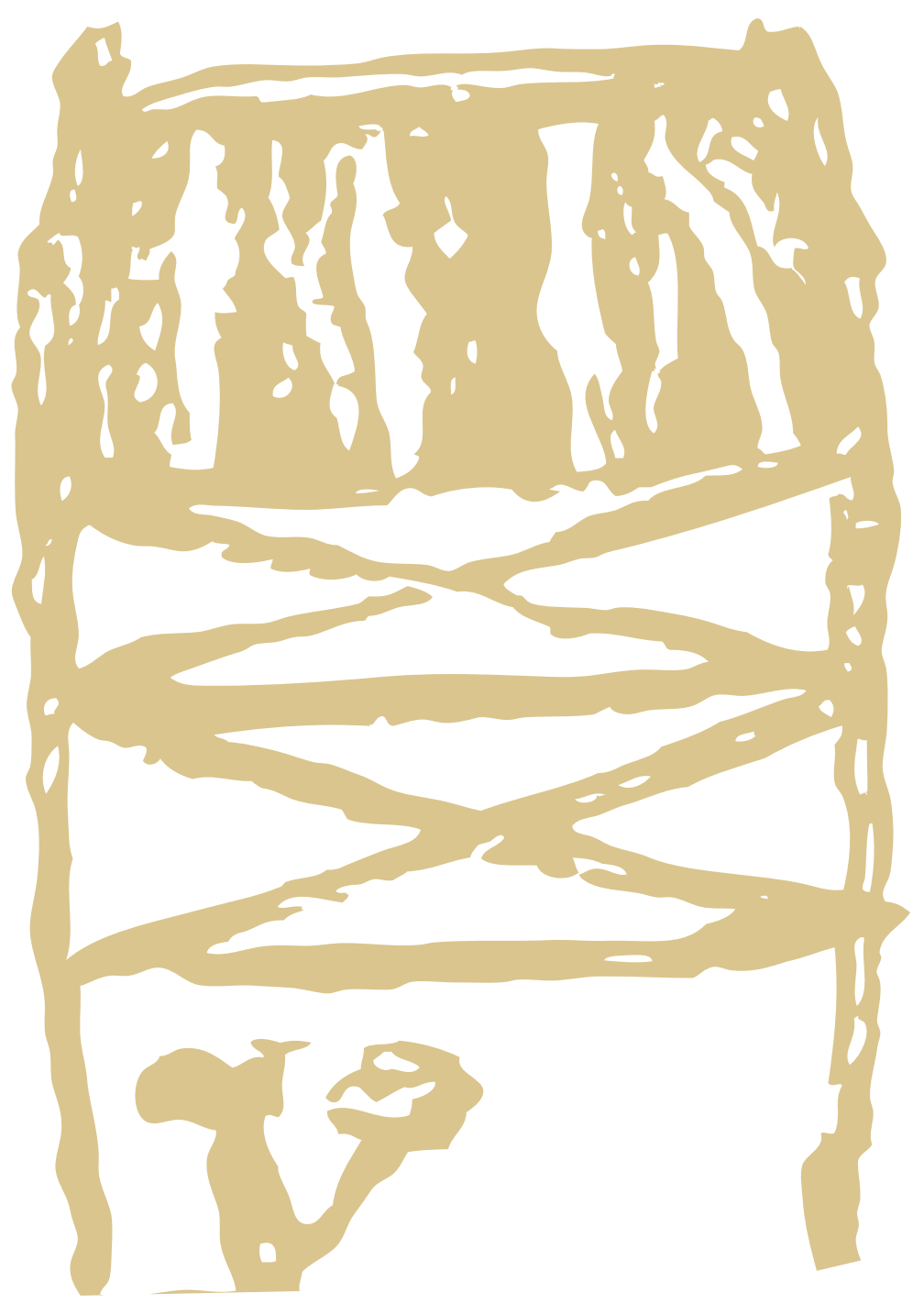

